\section{Nódulos Tireóideos: Guia Prático para Diagnóstico e Tratamento}

\begin{abstract}
A AVAliação e CONduta de um paciente portador de un nódulo tireóideo ainda é assunto bastante controverso. É difícil elaborar um modelo que possa ser aplicado a todos os casos. Nem sempre o que é melhor para um paciente ó ć para outro, pois devemos analisar cada caso individualmente $c$ vários fatores (idade, aspecto sócio-econômico, doenças concomitantes, motivos pessoais ou familiares) vão influenciar na escolha do tratamento adequado para cada caso. Para finalidade didática, compilamos um resumo dos principais tópicos utilizados para diagnóstico e opções de tratamento dos nódulos. Finalmente, sugerimos um guia prático para auxiliar a conduta frente a um paciente portador de nódulo da tireóide.
\end{abstract}

\section{DIAGNÓSTICO}

\author{
Avaliação Laboratorial: T4 livre \\ TSH \\ Tireoglobulina \\ Ac anti-TPO
}

Cintilografia e captação da tireóide com radioiodo ou tecnécio:

Indicado na suspeita clínica e laboratorial de nódulo autônomo.

Avaliação Ultra-sonográfica:

Em nossa opinião, deve ser realizado rotineiramente com a finalidade de confirmar o diagnóstico clínico, determinar as características macroscópicas do nódulo (contorno, ecogenicidade, presença de halo hipoecóico, áreas líquidas ou calcificações) e selecionar os nódulos suspeitos para a punção aspirativa por agulha fina (PAAF).

Classificação ultra-sonográfica dos nódulos tireóideos (tabela 1 ):

Grau I (score 1): pequena imagem anecóica arredondada, compatível com cisto de tireóide.

Grau II (score 2): nódulo de textura mista e imagens nodulares sólidas isoecóicas ou hiperecóicas de textura homogênea, acompanhadas ou não de calcificações grosseiras, componente líquido e com o restante do parênquima de textura homogênea, são compativeis com Bócio Colóide Adenomatoso; nódulo isoecóico, de textura homogênea, com halo hipoecóico periférico em tireóide de volume e ecogenicidade normais é sugestivo de Adenoma Folicular.

Grau III (score 3): nódulo hipoecóico, de contorno regular, sem calcificaçōes e nódulos císticos com componente sólido são considerados duvidosos.

Grau IV (score 4): nódulo sólido hipoecóico, de contorno impreciso e com microcalcificações é considerado suspeito para malignidade e sugestivo de câncer da tireóide.

\section{artigo original}

Geraldo Medeiros-Neto Rosalinda $\Upsilon$. A. de Camargo Eduardo Kiyoshi Tomimori
Recebido em 29/6/98

Revisado em 24/7/98 Aceito em 28/7/98 
Tabela 1: Classificação ultra-sonográfica dos nódulos tireóideos.

\begin{tabular}{|c|c|c|}
\hline Grau & imagem ecográfica & diagnóstico provável \\
\hline I (score 1) & pequena imagem anecóica arredondada & cisto de tireóide \\
\hline II (score 2) & imagens nodulares isoecóicas & $\begin{array}{l}\text { bócio colóide adeno- } \\
\text { matoso }\end{array}$ \\
\hline III (score 3) & nódulo sólido hipoecóico & neoplasia folicular \\
\hline IV (score 4) & $\begin{array}{l}\text { nódulo hipoecóico, contorno irregular e } \\
\text { microcalcificaçōes }\end{array}$ & câncer de tireóide \\
\hline
\end{tabular}

\section{Avaliação citológica}

Os exames citológicos são analisados, agrupados em padrões citológicos e então classificados, de acordo com as características citológicas em graus de I a IV e scores de 1 a 6 , sendo I benigno, II duvidoso, III suspeito para neoplasia e IV maligno.

Classificação citológica dos nódulos (tabela 2):

Grau I (score 1): padrão folicular com núcleos redondos ou ovalados, com cromatina densa e uniformemente distribuída, citoplasma eosinófilo e sem grânulos, grande quantidade de substrato protéico colóide e presença ou não de macrófagos fagocitando hemossiderina. O diagnóstico provável é Bócio Coloide Adenomatoso (BCA).

Grau II (score 2): padrão folicular com grande quantidade de células em arranjo sólido ou folicular, núcleos redondos ou ovalados com cromatina uniformemente distribuída, citoplasma levemente eosinófilo e sem grânulos e colóide escasso ou ausente. Esse padrão pode ser encontrado nas áreas adenomatosas do BCA ou nas neoplasias foliculares diferenciadas.

Grau III (score 3): padrão suspeito com grande quantidade de células que podem se apresentar isoladas, em blocos sólidos, em arranjo folicular ou papilífero, núcleos apresentando anisocariose (variação do volume nuclear), cromatina irregularmente distribuída e nucléolos, por vezes, proeminentes, cito- núcleos apresentam anisocariose, cromatina irregularmente distribuída, nucléolos proeminentes, presença de dobras da membrana nuclear e inclusão citoplasmática intra-nuclear.

Carcinoma Medular: grande quantidade de células isoladas ou agrupadas que podem se apresentar plasmocitóides, redondas, ovais, poligonais ou fusiformes. Os núcleos podem ser excêntricos e entre essas células neoplásicas pode se observar a presença de substância hialina e amorfa caracterizando o amilóide.

Carcinoma Anaplásico: grande quantidade de células isoladas ou agrupadas em arranjo sólido, com núcleos únicos ou múltiplos, de contornos irregulares, pleomórficos e com acentuado grau de anisocariose, cromatina grosseiramente distribuída e nucléolos proeminentes; mitoses atípicas ou aberrantes podem ser observadas.

Linfoma de tireóide: grande quantidade de células linfóides monomórficas.

Em nossa opinião, a avaliação final do nódulo deve se basear em suas características macroscópicas, definida através do exame ultra-sonográfico e em suas características microscópicas, obtidas através do exame citológico.

A classificação combinada (ultra-sonográfica + citológica) é dada pela soma dos scores da classificação

Tabela 2: Classificação citológica dos nódulos tireóideos

\begin{tabular}{lll}
\hline Grau & Padrão citológico & Diagnóstico provável \\
\hline I (score 1) & folicular com grande quantidade de colóide & bócio colóide \\
II (score 2) & folicular sem atipia nuclear com predomínio & nódulo adenomatoso \\
& de células e colóide escasso & neoplasia folicular \\
III (score 3) & suspeito com atipias nucleares e colóide escasso & neoplasia de tireóide \\
IV (score 6) & maligno & câncer de tireóide \\
\hline
\end{tabular}

plasma levemente eosinófilo e sem grânulos ou volumoso, eosinófilo e finamente granular, caracterizando células de Hürthle. O colóide é escasso ou ausente. Este padrão é sugestivo de neoplasia.

Grau IV (score 6): padrão citológico maligno:

Carcinoma Papilifero: grande quantidade de células em blocos sólidos ou em arranjo papilífero. Os ultra-sonográfica e citológica e resultam em índices que variam de 2 a 10 (tabela 3 ). Quanto maior o índice, maior a probabilidade de malignidade.

Os nódulos que obtiverem índice de 2 a 4 são considerados benignos. Os de índice 5 são considerados duvidosos e, em nossa experiência, com maior 
Tabela 3: Classificação combinada dos nódulos tireóideos.

\section{ÍNDICE}

DIAGNÓSTICO

Soma dos scores da classificação

ultra-sonográfica e citológica

$\begin{array}{cc}2 \text { a } 4 & \text { benigno } \\ 5 & \text { duvidoso } \\ 6 & \text { suspeito } \\ 7 \text { a } 10 & \text { maligno }\end{array}$

probabilidade de serem benignos, podendo ser acompanhados clinicamente. Já os nódulos que obtiverem índice igual ou maior que 6 deverão ser encaminhados à cirurgia, pois, em nossa experiência, 76\% deles corresponderam a carcinoma.

Os nódulos benignos ao ultra-som (grau I e II na classificação ultra-sonográfica) raramente são malignos e a PAAF não é procedimento obrigatório. Segundo alguns autores, a probabilidade de um nódulo isoecóico ser maligno é de $1 / 1000$.

\section{TRATAMENTO SUPRESSIVO COM LT4}

É assunto controverso e a literatura apresenta estudos randomizados, controlados com placebo, que indicam, paradoxalmente, efeito positivo da supressão de TSH no volume nodular ou nenhuma ação neste sentido. Em nossa experiência, os nódulos potencialmente responsivos são os de volume inicial menor que $2,4 \mathrm{~mL}$.

Dose: supressiva (em torno de $200 \mathrm{mg}$ de LT4)

Manter o TSH menor que $0,1 \mathrm{uU} / \mathrm{mL}$.

Tempo de tratamento: deverá ser mantido por 12 meses.

Reavaliação a cada 6 meses: tireoglobulina, volume do nódulo, volume total glandular.

O decréscimo de $50 \%$ do volume inicial encoraja a terapêutica prolongada, porém deve-se avaliar o risco de osteopenia.

Em caso de não resposta, discutir com o paciente outras alternativas de tratamento (etanol, cirurgia).

\section{TRATAMENTO COM INJEÇÃO PERCUTÂNEA DE ETANOL (IPE) GUIADA PELO ULTRA-SOM}

\section{Indicaçōes}

1.nódulos císticos ou mistos: pode ser a primeira opção terapêutica devido aos excelentes resultados obtidos ;

2 .nódulo autônomo: alternativa ao tratamento cirúrgico ou radioiodo;

3.nódulo atóxico benigno: redução de volume nos pacientes com alto risco cirúrgico.

\section{MÉTODO}

\section{Nódulo cístico ou misto:}

1. retirada do conteúdo líquido;

2. introdução de $30 \%$ do volume aspirado de etanol $95^{\circ}$ ou absoluto;

3. manter o etanol por 10 a 15 minutos e depois retirar;

4. repetir o procedimento após uma semana, se necessário.

\section{Nódulo sólido:}

1. injetar uma vez e meia o volume nodular, fracionada em várias sessões semanais;

2. não ultrapassar $5 \mathrm{ml}$ de etanol em cada sessão;

3. injetar o etanol o mais lentamente possível;

4. interromper a injeção quando o etanol atingir a cápsula nodular ou quando sentir resistência;

5. recomendamos anestesia local e o uso de anti-inflamatório não hormonal durante 1 ou 2 dias após o procedimento.

\section{TRATAMENTO DO BÓCIO MULTINODULAR ATÓXICO COM RADIOIODO}

Recentemente, tem-se demonstrado que o tratamento com radioiodo é uma alternativa à cirurgia para pacientes idosos portadores de bócio volumoso com sintomas compressivos.

Estudos que utilizam a ultra-sonografia e a ressonância magnética para determinação de volume tireóideo, demonstraram uma redução de volume de $40 \%$ após um ano e de 50 a $60 \%$ após 3 a 5 anos, com sensível melhora dos sintomas compressivos. tecido.

Dose de radioiodo preconizada: $100 \mathrm{uCi} / \mathrm{g}$ de

\section{Complicaçōes:}

- hipertireoidismo de causa autoimune: 5\% dos pacientes vários meses após o tratamento;

- hipotireoidismo: 20 a 30\% após 5 anos do tratamento.

Em pacientes idosos, especialmente aqueles portadores de doenças cardio-pulmonares, o tratamento com radioiodo pode ser uma alternativa à cirurgia. Será interessante, no futuro, avaliar se o uso de TSH recombinante aumentaria a eficácia do radioiodo, o que permitiria o seu uso em doses menores. 


\section{TRATAMENTO DO CÂNCER DIFERENCIADO DA TIREÓIDE COM RADIOIODO}

O Il31 é comumente utilizado como complemento do tratamento cirúrgico, tanto para ablação do tecido tireóideo remanescente quanto do tecido neoplásico residual.

Razões para a realizacão rotineira do radioido:

- ablação do microcarcinoma oculto no tecido remanescente;

- permite a detecão de neoplasia recorrente ou persistente, particularmente na região cervical, através da cintilografia;

- diminui o risco de recorrência e morte devido ao carcinoma da tiréoide;

- detecção e tratamento do carcinoma metastático;

- quando todo o tecido tireóideo normal é destruido, a tireoglobulina sérica se torna um bom marcador para carcinoma recorrente. de Il31.

A dose rotineiramente empregada é de $100 \mathrm{mCi}$

\section{Radioiodoterapia no tratamento de niveis ele- vados de tireoglobulina}

A tireoglobulina ( $\mathrm{Tg}$ ) é o melhor marcador para o carcinoma diferenciado após tireoidectomia total.

Cerca de $13 \%$ dos pacientes submetidos a tireoidectomia total apresenta tireoglobulina detectável com cintilografia negativa ( $80 \%$ deles com $\mathrm{Tg}<50 \mathrm{ng} / \mathrm{ml}$ ).

Possibilidades: tecido neoplásico sem capacidade de captar I 131 .

Captação muito baixa ou tecido muito pequeno

A cintilografia de corpo inteiro (PCI) após dose de $100 \mathrm{mCi}$ pode detectar focos com porentagem de captação muito baixa para serem visíveis com doses de 2 a $5 \mathrm{mCi}$.
Nível de tireoglobulina para tratamento com radioiodo: acima de $10 \mathrm{ng} / \mathrm{mL}$ em terapia supressiva.

Dose: $100 \mathrm{mCi}$ até obtenção de PCI negativa após terapia.

Esse procedimento promove efeitos terapêuticos c freqüientemente a cura definitiva, particularmente em pacientes com metástases pulmonares e RX de tórax negativo.

\section{CONDUTA NO MICROCARCINOMA DE TIREÓIDE}

Prevalência: 0,45 a $36,5 \%$.

Em nosso meio (São Paulo), a prevalência em matcrial de autópsia, é de $2,33 \%$.

Nódulos menores que $1 \mathrm{~cm}$ de diâmetro em pacientes que apresentam risco cirúrgico aumentado (idade avançada, diabetes, doenças cardio-pulmonares), podem ser acompanhados clinicamente com exame ultra-sonográfico e dosagem de tireoglobulina periódicos.

\section{Encaminhar à cirurgia}

Nódulos maiores que $1,0 \mathrm{~cm}$ de diâmetro. sentarem:

Nódulos menores que $1,0 \mathrm{~cm}$ que apre-

1. Invasão extra-tircóidea;

2. Nódulo situado próximo à cápsula da tireoide ou no ístmo;

3. Nódulo situado próximo ao nervo laríngeo recorrente;

4. Adenomegalia cervical;

5. Multicentricidade;

6. Suspeita de carcinoma pouco diferenciado à citologia;

7. Crescimento do tumor durante o período de observação.

Esquema. Normas gerais para conduta nos nódulos de tireóide.

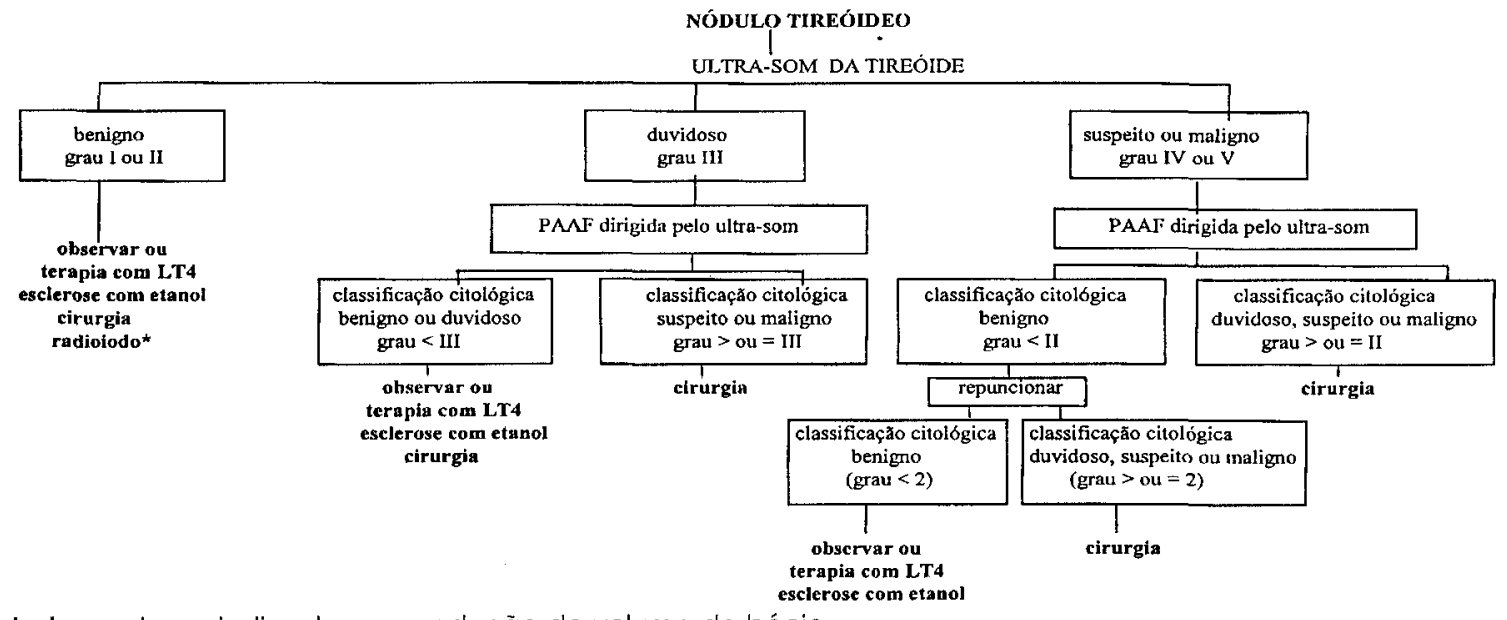

"radioiodo: pode ser indicado para redução de volume do bócio 


\section{BIBLIOGRAFIA}

1. Bisi H. Camargo RYA, Longatto Filho. Role of fine-needle aspiration cytology in the management of thyroid nocules: review of experience with 1925 cases. Diagn Cytopathol 1992; 8:504-10.

2. Bisi H, Fernandes VSO, Camargo RYA, Koch I, Abdo AH, Brito T. The prevalence of unsuspected thyroid pathology in 300 sequential autopsies, with special reference to the incidental carcinoma. Cancer 1989; 64:1888-93.

3. Brander A, Viikinkoski P. Tuuhea J, Voutilainen L, Kivisaari $L$. Clinical versus ultrasound examination of the thyroid gland in common clinical practice. J Clin Ultrasound 1992; 20:37-42.

4. Caraccio N, Goletti O, Lippolis PV, Cosalaro A, Cavina E, Miccoli $P$ and Monzani F. Is percutaneous ethanol injection a useful alternative for the treatment of the cold benign thyroid nodule? Five years 'experience. Thyroid 1997; 7(5):699-704.

5. Carroll AB. Asyntomatic thyroid nodules: Incidental sonographic detection. Am J Roentg 1982; 138:499-501.

6. Hamburger Jl. Thyroid disease. In Clinical exercises in internal medicine, Philadelphia: WB Saunders 1978; vol l:221.

7. Harlocker $\Pi$, Hay JE, James EM, Reading CC, Charboneau WJ. Prevalence of incidental nodular thyroid disease detected during high-resolution parathyroid ultrasonography. In: Medeiros-Neto GA, Gaitan E (eds) Frontiers in Thyroidology, vol. 2, Plenum Press, New York 1986; $p 1309$.

8. Huysmans D, Hermus A, Edelbroek M, Barentsz J Corstens F, Kloppenborg P. Radiodine for Nontoxic Multinodular Goiter.Thyroid 1987; 7(2): 235-9.

9. Klima. L'échographie de la thyroïde. Deuxième édition. Urban\&Schwarzenberg 1995.

10. La Rosa GL, Ippolito AM, Lupo L. Cercabene $G$. Santonocito MG, Vigneri R, Belfiore. Cold thyroid nodule reduction with $L$-thyroxine can be predicted by initial thyroid volume and cytological characteristics. J Clin Endocrinol Metab 1996; 81:4385-7.

11. Lippi F, Ferrari C, Manetti I, Rago T, Santini F, Monzani F, Bellitti P. Papini E, Busnardo B, Angelini F, Pinchera A. Treatment of solitary autonomous thyroid nodules by percutaneous ethanol injection: results of an italian multicenter study. J Clin Endocrinol Metab 1996; 81:3261-4.

12. Lima N, Knobel M, Cavaliere H, Sztejnsznadj C, Tomimori $E$, Medeiros-Neto $G$. Levothyroxine supressive therapy is -partially effective in treating patients with benign, solid thyroid nodules and multinodular goiters. Thyroid 1997; 7(4): $691-7$.
13. Müller HW, Schröder S, Schneider C, Seifert G.: Sonographic tissue characterisation in thyroid gland diagnosis. A correlation between sonography and histology. Klin Wochenschr 1985; 63:706-10.

14. Papini E, Bacci V, Panunzi C, Pacella CM, Fabbrini R, Bizarri G. Petrucci L, Gianmarco V, La Medica P. Masala $M$. Pitaro $M$, Nardi $F$. A prospective randomized trial of levothyroxine suppressive therapy for solitary thyroid nodules. Clin Endocrinol (Oxf) 38:507-13.

15. Schlumberger M, Mancusi F, Budin E, Pacini F. 1311 therapy for elevated thyroglobulin levels.Thyroid, 1997; 7(2).

16. Stark DD, Clark DH. Gretchen A, Goodina W, Moss AA. High-resolution ultrasonographic and computed tomography of thyroid lesions in patients with hyperparathyroidism. Surgery 1984; 94:863-8.

17. Tan GH. Gharib H. Thyroid Incidentalomas: Management approaches to nonpalpable nodules discovered incidentally on thyroid imaging. Ann Intern Med 1997; 126:226-31.

18. Tomimori EK, Pedrinola $F$, Cavaliere $H$, Knobel $M$, Medeiros-Neto GA. Prevalence of incidental thyroid disease in a relatively low jodine intake area. Thyroid 1995; $5(4): 273-6$.

19. Verde G, Papini E, Pacella CM, Galloti C, Delpiano S, Strada S, Fabbrini R, Bizzarri G, Rinaldi R, Panunzi C, Gelli $D$. Ultrasound guided percutaneous ethanol injection in the treatment of cystic thyroid nodules. Clinical Endocrinology 1994; 41: 719-24.

20. Woolner LB, Lemmon ML, Beahrs OH et al. Occult papillary carcinoma of the thyroid gland. A study of 140 cases observed in a 30 years period. J Clin Endocr Metab 1960; 20:89-105.

21. Yokozawa T, Miyauchi A, Kuma K. Sugawara M. Accurate and simple method of dlagnosing thyroid nodules by the modified technique of ultrasound-guided fine needle aspiration biopsy. Thyroid 1995; 5(2): 141-5.

22. Yokozawa T, Fukata S, Kuma K, Matsuzuka F, Kobayashi A. Hirai K. Miyauchi A, Sugawara M. Thyroid cancer detected by ultrasound -guided fine-needle aspiration biopsy. World J Surg 1996; 20:848-853.

\section{Endereço para correspondência:}

Unidade de Tireóide, Disciplina de Endocrinologia Hospital das Clínicas da Faculdade de Medicina da USP Caixa Postal 3671

01060-970 São Paulo, SP.

Fone: 282-8522 Fax: $211-3367$

Email: tireóide@uol.com.br /uspaaf@uol.com.b 